\title{
Electron Microscopic Study of Macrophages Appearing in a Stab Wound of the Brain of Rats Following Intravenous Injection of Carbon Particles
}

\author{
E. A. LING \\ Department of Anatomy, University of Singapore Faculty of Medicine, Sepoy Lines, Singapore
}

Received May 22, 1978

\begin{abstract}
Summary. Colloidal carbon was introduced intravenously into young rats to label circulating monocytes before the stabbing of the brain. The rats were sacrificed 1 to 14 days after the stab wound. In the rats sacrificed between 3 to 7 days after the stabbing, numerous phagocytic cells were present in the needle wound. Electron microscope study showed that some of these phagocytic cells carried intracytoplasmic carbon particles. These carbon-labelled cells showed features either of a monocyte, full-blown macrophages, or typical microglia. It is believed that they are all derived from circulating monocytes which have ingested carbon particles in circulation and thereafter invaded the stab wound.
\end{abstract}

In the past few years, it has been demonstrated repeatedly that some of the macrophages appearing in damaged and degenerating neural tissue originate from circulating monocytes (AdRiAn and W ALKER, 1962; KonigSMARK and SidMAN, 1963; Olsson and Sjostrand, 1964; Huntington and Terry, 1966; Adrian and Smothermon, 1970; Kitamura, Hattori and Fujita, 1972; Adrian and Williams, 1973). The results of the above-mentioned workers are primarily based on radioautographic studies in which ${ }^{3} \mathrm{H}$-thymidine was used to label circulating monocytes in different animals before damaging the nervous tissues in various ways, e.g. by stab wound (HunTINGTON and Terry, 1966; Kitamura et al., 1972; Kitamura, 1973). A more direct approach was by Iмамото and LeBLond (1977) who labelled bone marrow cells in vitro with ${ }^{3} \mathrm{H}$-uridine, and injected them into a recipient rat with a cortical lesion. With this method, they have shown the entry of uridine-labelled monocytes into the site of the lesion and their transformation into macrophages which would subsequently evolve to become microglia.

The validity of radioautography is definite but the method is cumbersome. Recently, a simpler method has been utilized by the present author for the same purpose in demonstrating the haematogenous origin of neural macrophages. In this method, a single or multiple dose of Indian ink is injected intravenously into rats labelling as many as possible the circulating monocytes. Following the injection, a time interval of $24 \mathrm{hrs}$ is allowed for clearance of free carbon in the blood, for it has been shown that free carbon disappears within a few hours after the injection (BenACERRAF et al., 1957; Stenwig, 1972), probably picked up by cells of the reticuloendothelial system (LING, unpublished observations). Any subsequent carboncontaining cells which appear in the damaged neural tissue are therefore derived 
from blood elements which have ingested carbon particles in circulation. In this connection, both monocytes and polymorphonuclear leucocytes are found to be labelled with intravenous carbon but they are readily distinguished by nuclear morphology under both the light and electron microscope. With this method, the entry of monocytes and their transformation into macrophages in the Wallerian degeneration of the optic nerve have been shown in rats (LiNG, 1978b), and also in the spinal cord of rats subjected to dorsal rhizotomy (LiNG, 1978c).

The present study further confirms the contribution of monocytes in the formation of macrophages which appear in a stab-wound of the brain inflicted on the cerebral cortex and corpus callosum. Carbon-containing cells are clearly demonstrated at the site of the lesion.

\section{MATERIALS AND METHODS}

Ten young albino rats weighing approximately $60 \mathrm{~g}$ were used. Each rat was given, at a $24 \mathrm{hr}$-interval, two doses of carbon suspension (Günther Wagner Pelikan Ink of Hannover, Germany; Batch No. C11-1431a) into the jugular vein under ether anesthesia. For each injection, $0.5 \mathrm{ml}$ of carbon suspension was used. Twenty-four hrs after the second injection, the rat was inflicted with a stab wound. A 23-gauge needle was inserted vertically downwards after drilling a small hole approximately $1 \mathrm{~mm}$ to the left of the sagittal suture and immediately posterior to the coronal suture. The needle was pushed to the base of the skull traversing the cortex, subependyma and caudal nucleus. The rats were sacrificed at 1, 2, 3, 4, 5, 7, 9, 12 and 14 days postoperatively. They were perfused with a mixed aldehyde solution composed of $2 \%$ paraformaldehyde and $3 \%$ glutaraldehyde in $0.1 \mathrm{M}$ cacodylate buffer, $\mathrm{pH}$ 7.3. Blocks of the cerebral cortex and corpus callosum together with its subjacent subependyma including the needle passage were cut out and post-osmicated in Dalton's fluid. They were dehydrated in the usual manner and embedded in araldite mixture. Semithin sections stained with toluidine blue were prepared from all animals for general survey. Since preliminary observations showed that carbon-containing cells were most numerous in rats sacrificed between 3 to 7 days after the operation, materials from these cases were processed for electron microscopic study. Ultrathin sections were cut on a Porter-Blum ultramicrotome, stained with uranyl acetate and lead citrate and examined in a Hitachi HS-8 electron microscope.

\section{OBSERVATIONS}

\section{Cerebral cortex}

In the rats injected with intravenous carbon particles and sacrificed between 3 to 7 days after the stab wound, numerous carbon-labelled cells were present within and in the marginal area of the needle passage. Some of them were also observed deep in the neuropil far from the wound area. These cells displayed diverse morphological forms most of which were clearly macrophagic as shown by their massive phagosomes, while others were relatively free from such inclusions. Based on the amount of the cytoplasmic inclusions, nuclear and cell shapes, it was possible to clas- 


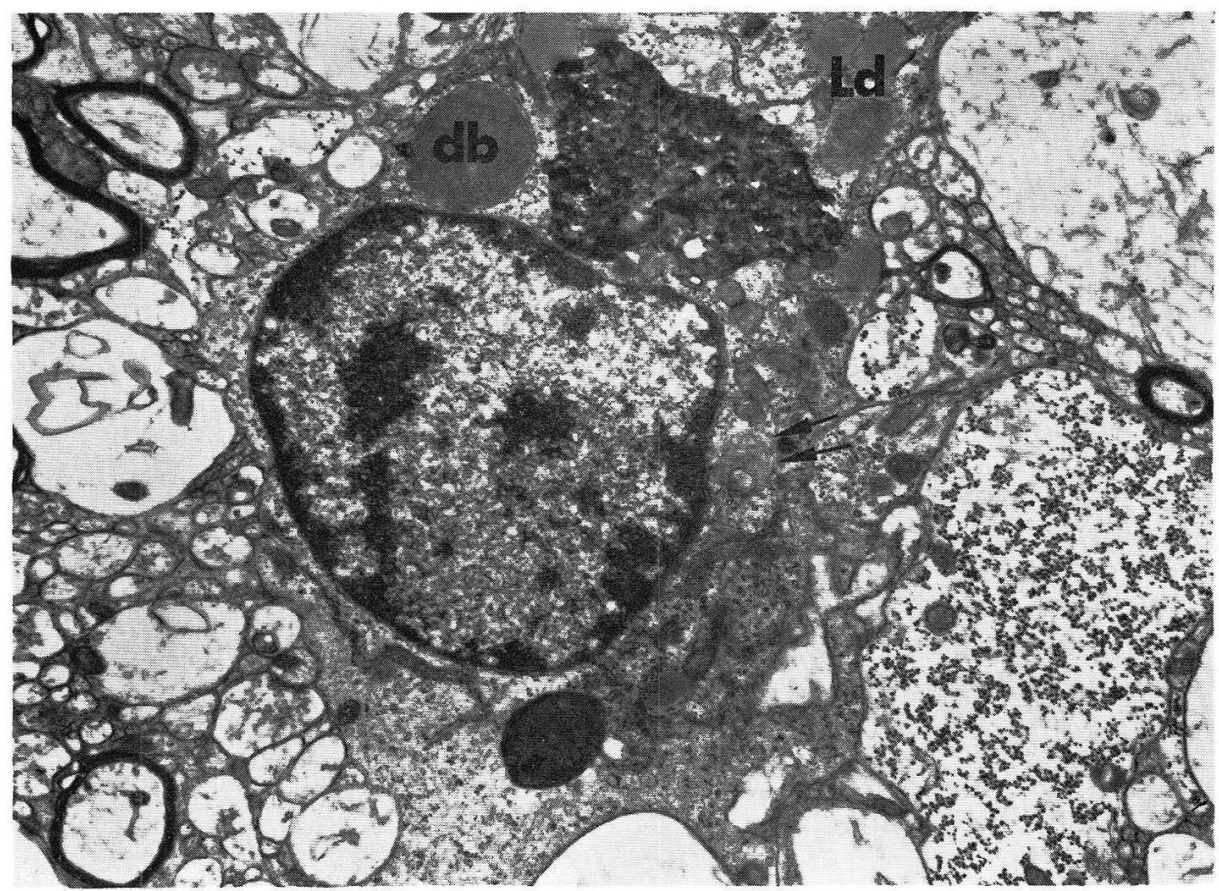

Fig. 1. A Type I carbon-labelled cell in the neuropil some distance away from the needle passage. The cell is relatively devoid of phagosomes. A large mass of carbon particles is shown just above the nucleus. Polyribosomes are widely dispersed throughout the cytoplasm. Dense body $(d b)$ and a few lipid droplets $(L d)$ are present. Arrows indicate bundles of microfilaments. $\times 15,000$

sify the carbon-labelled cells into three categories, although transitional cells between the three cell types were also observed.

\section{Type I carbon-labelled cells}

In semithin sections stained with toluidine blue, these cells were most frequent soon after the stab wound, i.e. 2 and 3 days after the operation. They could be identified in the semithin sections by the absence of phagocytic inclusions from the relatively homogenous cytoplasm other than by the carbon content.

Under the electron microscope, these cells displayed a regular nucleus, with an occasional indentation, bearing coarse chromatin masses (Fig. 1). Their cytoplasm showed little phagosomes and lipid droplets. Polyribosomes were widely dispersed but profiles of rough endoplasmic reticulum were rare. A striking feature of the cytoplasm was the presence of microfilaments (Fig. 1).

The number of this cell type apparently decreased with longer survival periods as they were rarely encountered in rats sacrificed at 5 and 7 days postoperation and were never observed at 9 days after the stab wound.

\section{Type II carbon-labelled cells}

These cells were most common in rats sacrificed between 3 to 7 days after the stab wound. Their copious cytoplasm was characterized by massive pleomorphic cyto- 


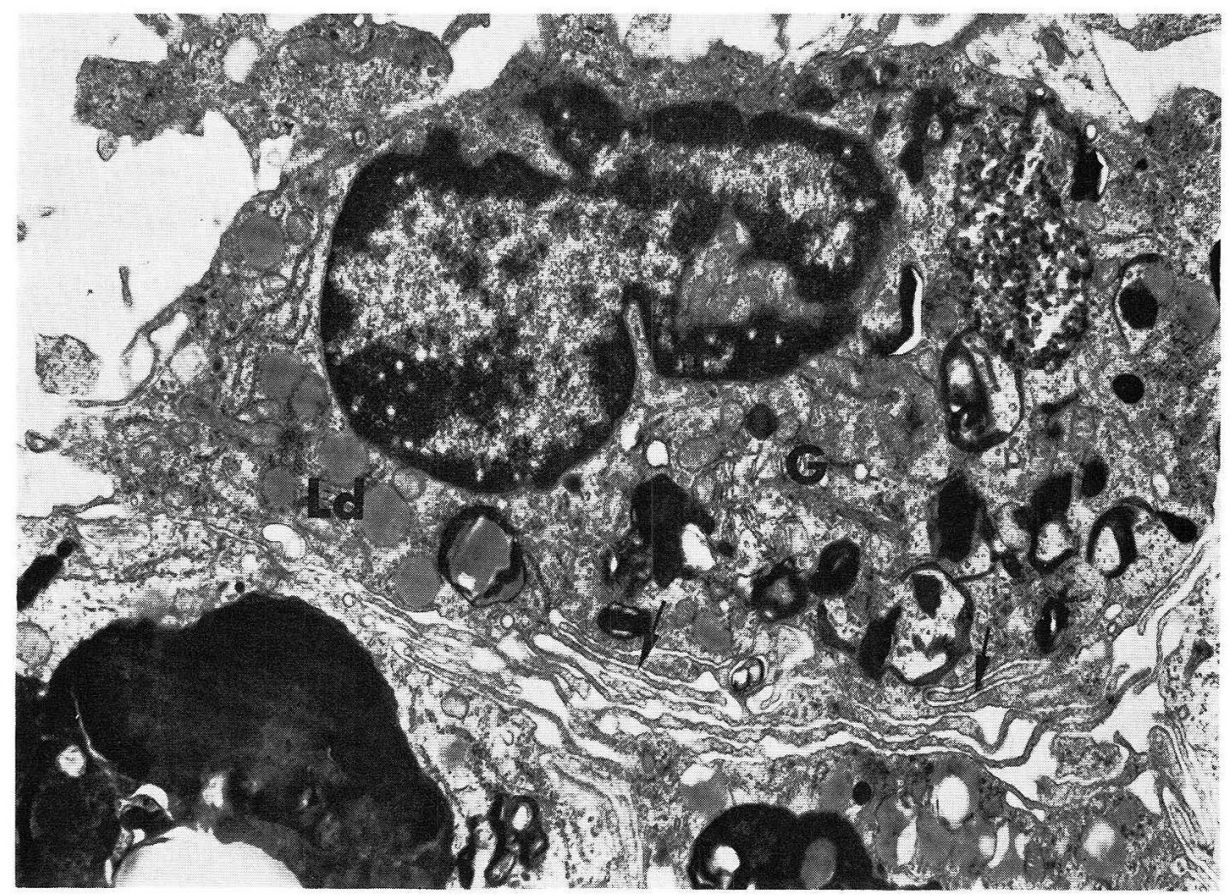

Fig. 2. A Type II carbon-labelled cell in the marginal zone of the needle passage. The indented nucleus displayed coarse chromatin clumps. A Golgi complex $(G)$ is located near the indentation of the nucleus. The cytoplasm is packed with abundant phagosomes and lipid droplets $(L d)$. Carbon particles in a large mass are to the right of the cell. Slender filopodial processes are seen projecting from the surface (arrows). $\times 15,000$

plasmic debris and lipid droplets (Fig. 2). A prominent Golgi complex was present in the paranuclear zone (Fig. 2). Their indented nucleus carried coarse chromatin clumps. Rough endoplasmic reticulum was in single isolated profiles which were confined to the periphery of cell. At the surface, numerous filopodial processes projected in different directions (Fig. 2).

\section{Type III carbon-labelled cells}

These were elongated cells bearing an angular (Fig. 3) or flattened (Fig. 4) nucleus. They were more common in the area where the neuropil was compact or in a healing wound at longer survival periods, i.e. after 7 days postoperation. The cytoplasm was of moderate amount (Fig. 3) or scanty accumulating on both poles of the cell (Fig. 4). A few electron dense bodies, presumably lysosomes, were present (Fig. 3, 4). The Golgi body displayed long and slender lamellae (Fig. 3).

\section{Corpus callosum and subependyma}

Between three to seven days after the stab wound, Type II carbon-labelled cells con-

Fig. 4. A Type III carbon-labelled cell in the neuropil far removed from the needle wound. The flattened nucleus displays marginal chromatin masses. The cytoplasm is scanty containing a prominent cluster of carbon particles $(c)$. A slender pseudopodial process extends into the interstices of the neuropil on the right (arrows). $\times 10,500$ 


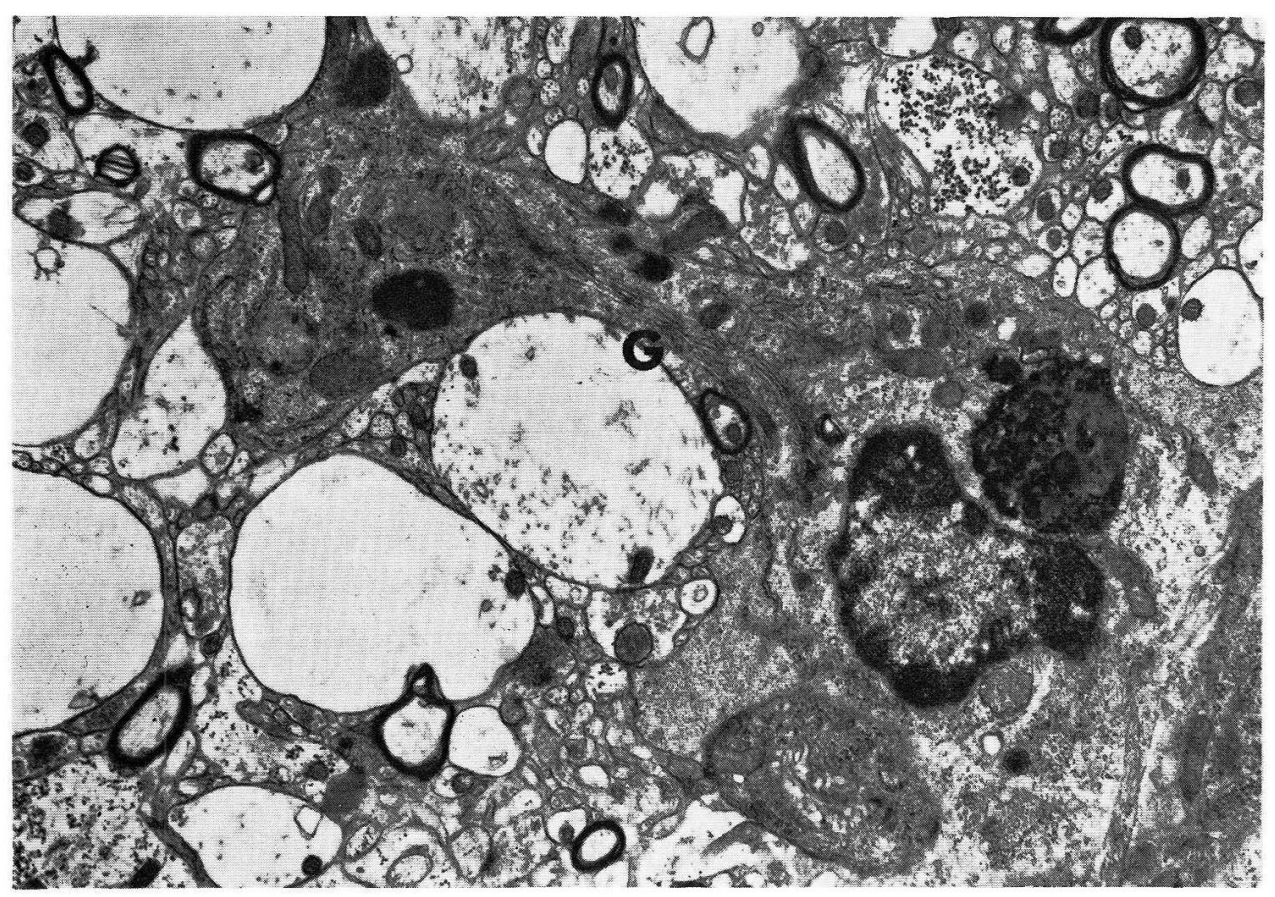

Fig. 3. A Type III carbon-labelled cell in the neuropil outside the needle wound. A large carbon mass which is partially dissoluted is seen above the angular nucleus. The cell is elongated with a long cytoplasmic extension toward the left. Golgi complex $(G)$ with flattened lamellae is well developed. $\times 15,000$

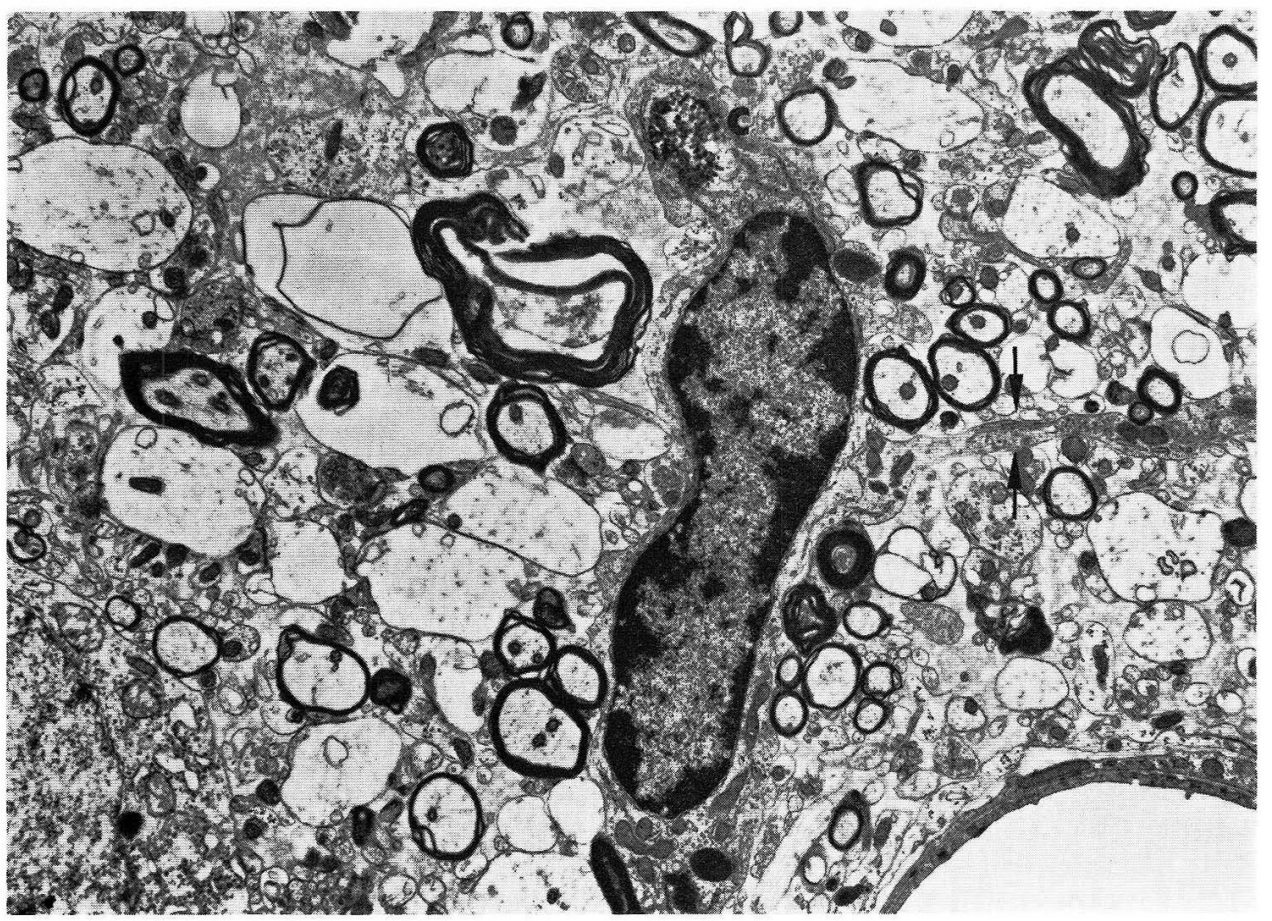

Fig. 4. Legend in opposite page. 


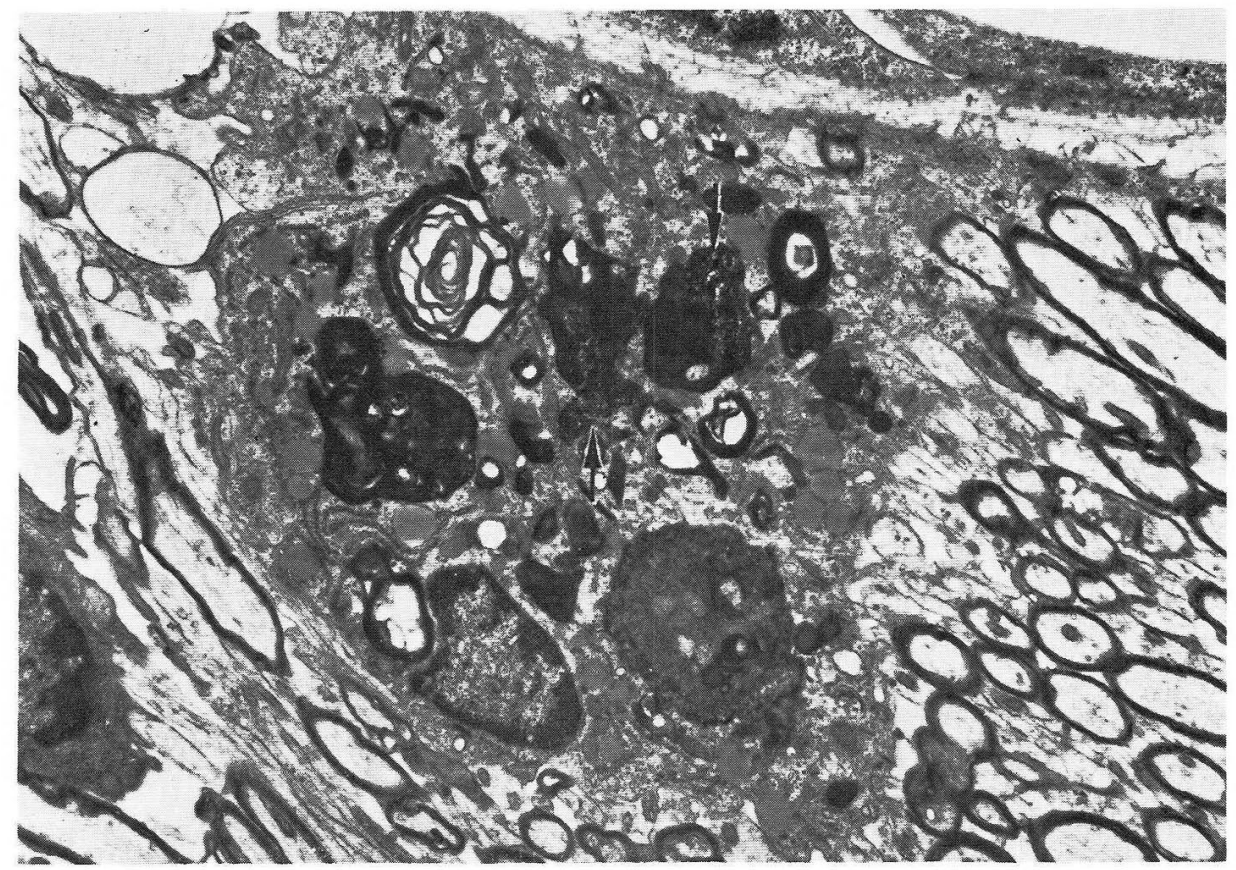

Fig. 5. A Type II carbon-labelled cell loaded with phagosomes and lipid droplets in corpus callosum. Carbon particles are incorporated in the very dense phagosomes (arrows). $\times 10,500$

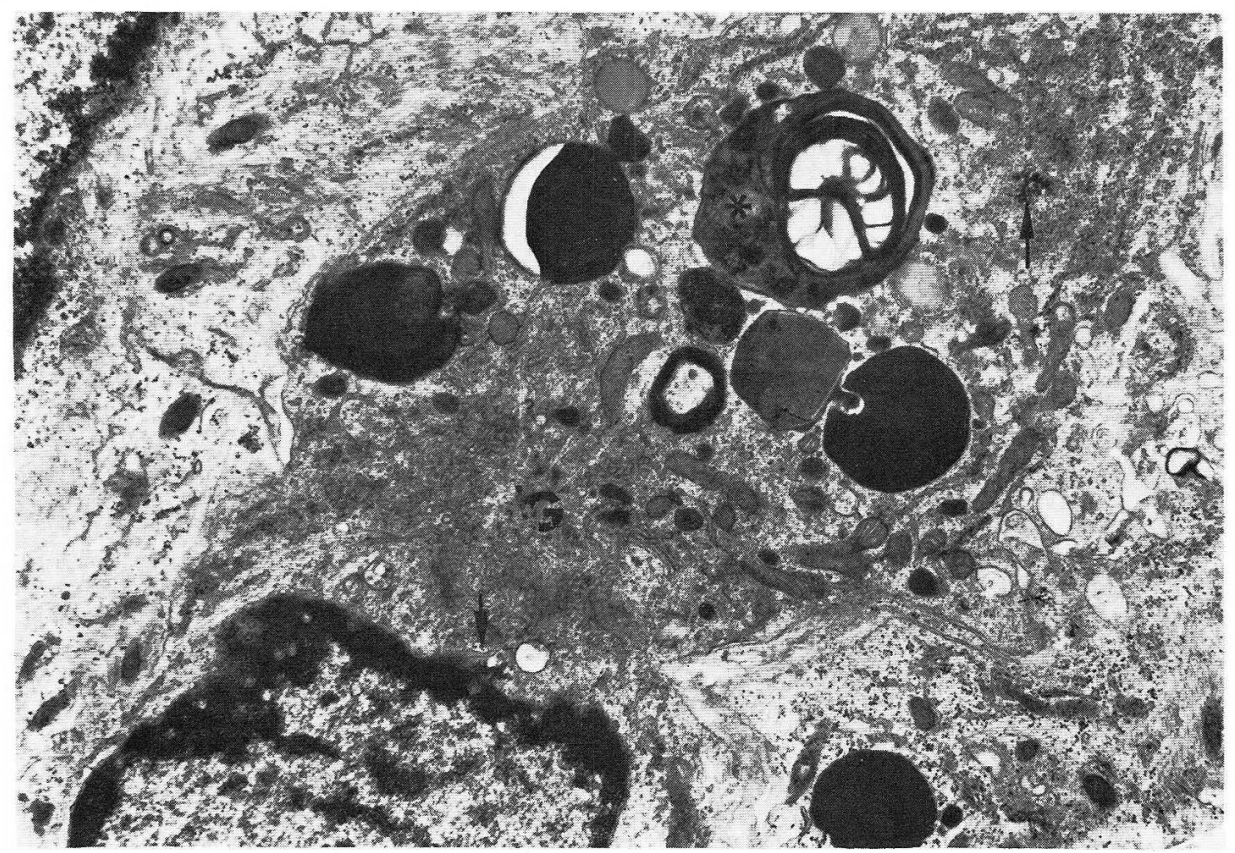

Fig. 6. A Type II carbon-labelled cell in corpus callosum. Two small clusters of carbon particles (arrows) are present. Some carbon particles are also observed in the matrix of the dense phagosome marked with an asterisk. In this particular macrophage, a prominent Golgi complex $(G)$ is next to the nucleus. Portions of astrocytes containing abundant microfilaments and glycogen particles are seen on both sides of the macrophage. $\times 15,000$ 


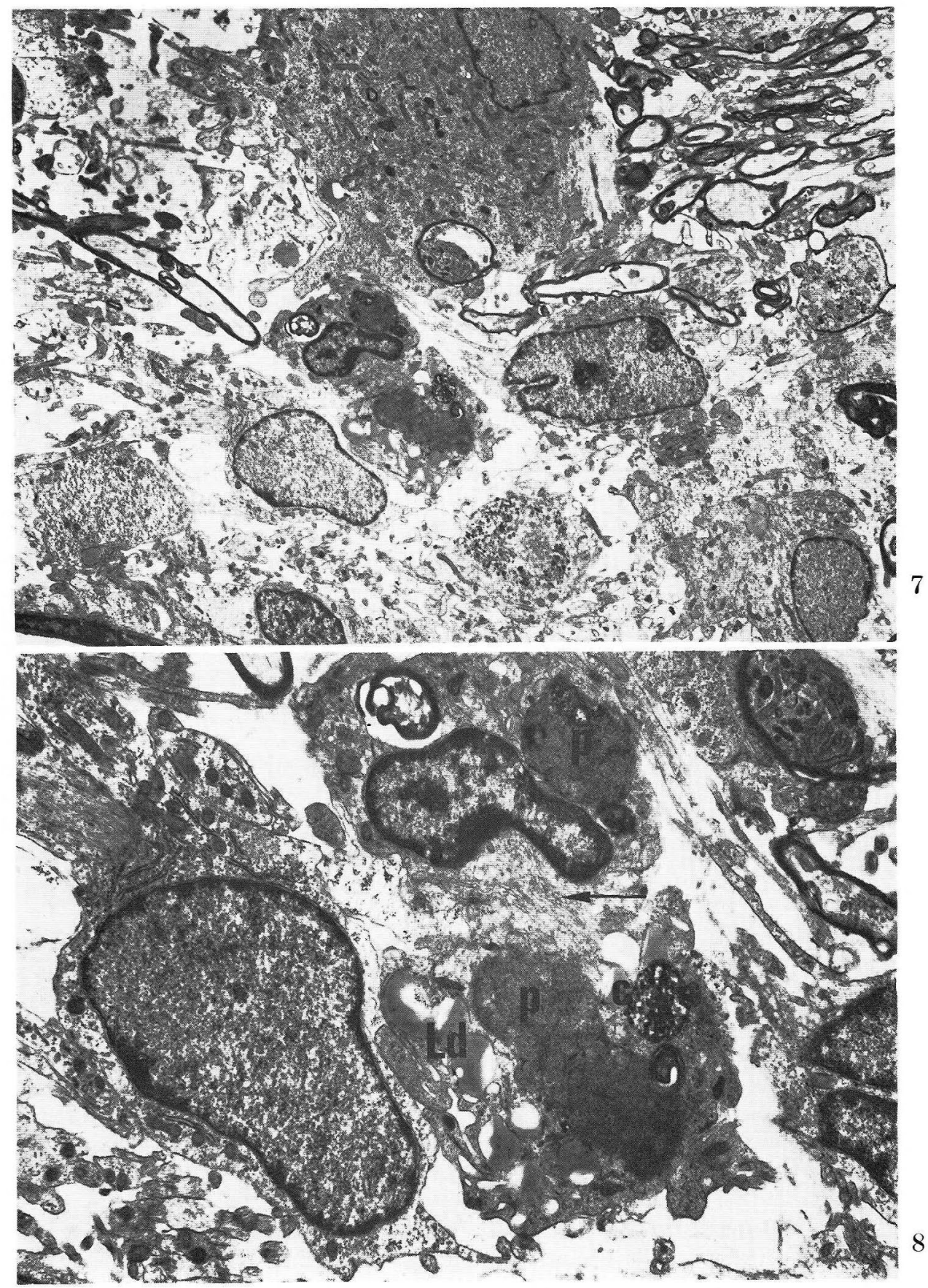

Fig. 7 and 8. A Type II carbon-labelled cell at different magnification in the subependyma near the lateral ventricle. Figure 7 shows a general view of the location of the cell. Immature cells are present. Figure 8 shows the presence of carbon mass $(c)$ in the cytoplasm. Other inclusions are phagosomes $(p)$ and lipid droplets $(L d)$. Arrow indicates a well-developed Golgi complex at the indentation of the nucleus. $\times 15,000$ 
taining intracytoplasmic carbon particles were also observed in the corpus callosum and subependyma. Their cytoplasm was loaded with phagosomes of various textures (Fig. 5-8). The carbon particles considerably varied in amount from cell to cell. For example, the cell depicted in Figure 6 contained only a few carbon particles. In the subependyma, carbon-labelled cells were present among immature cells, i.e. glioblasts (Fig. 7). In all these cells, a prominent Golgi complex was present (Fig. 6, 8).

\section{DISCUSSION}

The question of the origin of macrophages in degenerating neural tissue has been the subject of many investigations. Two general hypotheses have been proposed. The first school of thought believes that brain macrophages are of ectodermal origin, in particular subependymal cells (Rydberg, 1932; Lewis, 1968; Vaughn and Peters, 1968; VAughn et al., 1970). The other school of theory is based on Rio-Hortega's original observations (RIo-HorTEGA, 1919, 1932) in which he was able to follow the invasion of mesodermal elements from the brain surface into its substance by amoeboid movement. This view that brain macrophages are cells of mesodermal origin has been supported subsequently by many workers using radioautography (Konigsmark and Sidman, 1963; Huntington and Terry, 1966; Kitamura et al., 1972; IмAмото and LeBLOND, 1977, 1978). Thus, it has been shown that circulating monocytes are the candidate cells which may give rise to brain macrophages both under normal and experimental circumstances. For example, the work of Kitamura (1973) in mice shows that ${ }^{3} \mathrm{H}$-thymidine-labelled monocytes appear in lesions within $74 \mathrm{hrs}$ after a cortical stab wound. These cells soon metamorphose to become macrophages which are also labelled.

The present investigation together with those done earlier (LiNG, 1978a, b, c, d), in which colloidal carbon particles are used as an intracellular marker demonstrate unequivocally the infiltration of circulating monocytes and their transformation into macrophages in the normal and damaged neural tissues of rats. Thus, the hypothesis of a mesodermal origin of neural macrophages propounded by Rio-HoRTEGA early in this century $(1919,1932)$ is greatly amplified.

In the present investigation, when the cerebral cortex and corpus callosum were subjected to a stab wound, abundant phagocytic cells of diverse morphological forms appeared at the site of lesion. These cells ware present in the needle passage and in the marginal zone where the needle was inserted. Electron microscope study has clearly shown that some of these cells carried intracytoplasmic carbon particles. These carbon-labelled cells must have been derived originally from circulating monocytes which have ingested carbon particles following intravenous administration. In this instance, it is known that polymorphonuclear leucocytes could also ingest carbon particles introduced intravenously (LING, unpublished observation). However, their participation in the formation of macrophages in the stab-wound brain is dubious as they were only rarely observed. Polymorphonuclear leucocytes can be identified with certainty under the electron microscope by their nuclear shape and cytoplasmic granules specific to the cell types.

The immediate response of the carbon-labelled monocytes which have infiltrated the site of a lesion would be a transformation into macrophages by accumulating 
numerous phagosomes. In this connection, the Type I carbon-labelled cells which appear initially after the stab wound probably represent monocytes which have recently migrated into the degenerating tissue since they show only little phagocytic inclusions apart from their carbon content. Furthermore, the presence of microfilaments in their cytoplasm characterizes one of the features of a monocyte since, according to BLAKEMORE (1972), monocytes entering the rat cerebral cortex following a thermal lesion display cytoplasmic microfilaments although these would disappear subsequently.

The Type II carbon-labelled cells are considered to be full-blown macrophages as shown by the large amount of cytoplasmic debris. It is believed that they are derived from the transformation of the carbon-labelled monocytes by ingesting more and more degenerating elements but still carrying with them the carbon particles.

Finally, the presence of the Type III carbon-labelled cells in the stab wound at longer survival periods of the animals is interesting as they show all the morphological features of a typical microglia observed in normal rats (LING et al., 1973). In fact, the cell shown in Figure 4 is indistinguishable from a typical microglia. This would suggest that with time, carbon-labelled monocytes could also give rise to typical microglia as postulated by Iмамото and LEBLOND (1977). Evidence for a monocytic origin of typical microglia has also been described in early postnatal rats (ImAmoto and Leblond, 1978; Ling, 1978d).

\section{REFERENCES}

Adrian, E. K. and R. D. Smothermon : Leucocytic infiltration in the hypoglossal nucleus following injury to the hypoglossal nerve. Anat. Rec. 166: 99-116 (1970).

Adrian, E. K. and B. E. Walker : Incorporation of thymidine- $\mathrm{H}^{3}$ by cells in normal and injured mouse spinal cord. J. Neuropathol. exp. Neurol. 21: 597-609 (1962).

Adrian, E. K. and M. G. Williams : Cell proliferation in injured spinal cord. An electron microscopic study. J. comp. Neurol. 151: 1-24 (1973).

Benacerraf, B., G. Biozzi, B. N. Halpern and C. Stiffel: Physiology of phagocytosis of particles by the R. E. S. In: (ed. by) B. N. Halpern, B. Benacerraf and J. F. Delafresnaye: Physiology of the reticulo-endothelial system. Blackwell Scientific Publ., Oxford, 1957. (p. 52-79).

Blakemore, W. F.: Microglial reactions following thermal necrosis of the rat cortex: An electron microscopic study. Acta neuropathol. 21: 11-22 (1972).

Huntington, H. W. and R. D. Terry: The origin of the reactive cells in the cerebral stab wounds. J. Neuropathol. exp. Neurol. 25: 646-653 (1966).

Imamoto, K. and C. P. Leblond : Presence of labelled monocytes, macrophages and microglia in a stab wound of the brain following an injection of bone marrow cells labelled with ${ }^{3} \mathrm{H}$-uridine into rats. J. comp. Neurol. 174: 255-280 (1977).

- 1 : Radioautographic investigation of gliogenesis in the corpus callosum of young rats. II. Origin of microglial cells. J. comp. Neurol. 180: 139-164 (1978).

Kitamura, T.: The origin of brain macrophages-some considerations on the theory of del RioHortega. Acta pathol. jap. 23: 11-26 (1973).

Kitamura, T., H. Hattori and S. Fujita: Autoradiographic studies on histogenesis of brain macrophages in the mouse. J. Neuropathol. exp. Neurol. 31: 502-518 (1972).

Konigsmark, B. W. and R. L. Sidman: Origin of brain macrophages in the mouse. J. Neuropathol. exp. Neurol. 22: 643-676 (1963). 
Lewis, P. D.: The fate of the subependymal cell in the adult rat brain with a note on the origin of microglia. Brain 91: 721-735 (1968).

Ling, E. A.: Brain macrophages in rats following intravenous labelling of mononuclear leucocytes with colloidal carbon. J. Anat. 125: 101-106 (1978a).

-: Electron microscopic studies of macrophages in Wallerian degeneration of rat optic nerve after intravenous injection of colloidal carbon. J. Anat. 126: 111-121 (1978b).

-: Evidence for a haematogenous origin of some of the macrophages appearing in the spinal cord of the rat after dorsal rhizotomy. J. Anat. (In press, 1978c).

Ling, E. A.: Transformation of monocytes into amoeboid microglia and into microglia in the corpus callosum of newborn rats, as shown by labelling monocytes by carbon particles. J. Anat. (Accepted for publication, 1978d).

Ling, E. A., J. A. Paterson, A. Privat, S. Mori and C. P. Leblond: Investigation of glial cells in semithin sections. I. Identification of glial cells in the brain of young rats. J. comp. Neurol. 149: 43-72 (1973).

Olsson, Y. and J. Sjostrand: Origin of macrophages in Wallerian degeneration of peripheral nerves demonstrated autoradiographically. Exp. Neurol. 23: 102-112 (1964).

Rio-Hortega, P. Del : El 'tercer elemento' de las centros nerviosos. I. La microglia en estado normal. II. Intervencio de la microglia en los procesos patologicos. III. Naturaleza probable de la microglia. Bol. Soc. Esp. Biol. 9: 69-120 (1919).

: Microglia. In: (ed. by) W. Penfield: Cytology and cellular pathology of the nervous system P. B. Hoeber, New York, 1932.

Rydberg, E. : Cerebral injury in new-born children consequent on birth trauma; with an injury into the normal and pathological anatomy of the neuroglia. Acta pathol. microbiol. scand. 10 (Suppl.): 153-166 (1932).

Stenwig, A. E.: The origin of brain macrophages in traumatic lesions, Wallerian degeneration and retrograde degeneration. J. Neuropathol. exp. Neurol. 31: 696-704 (1972).

Vaughn, J. E., P. L. Hinds and R. P. Skoff : Electron microscopic studies of Wallerian degeneration in rat optic nerve. I. The multipotential glia. J. comp. Neurol. 140: 175-206 (1970).

Vaughn, J. E. and A. Peters: A third neuroglial cell type. An electron microscopic study. J. comp. Neurol. 133: 269-288 (1968).

Dr. E. A. Ling

Department of Anatomy

Faculty of Medicine

University of Singapore

Sepoy Lines

Singapore 3 